\title{
OPAK BİR YÜZEY ÜZERINNDEKİ DAİRESEL AÇIKLIKTAN SAÇILAN ALANLARIN HESABI
}

Mustafa ALTINEL

Ŭ̈ur YALÇIN

Alınma: 20.02.2021; düzeltme: 20.05.2021; kabul: 06.07.2021

Öz: Bu çalışmada, Sınır Kırınım Dalgası Teorisi (SKDT) yaklaşımı kullanılarak opak bir yüzey üzerindeki dairesel açıklıktan saçılan alanların hesabı incelenmiştir. İlk olarak, Miyamoto ve Wolf tarafından ortaya konulan vektör potansiyelinin sembolik ifadesi, SKD Teorisi integralinde kullanılmıştır. $\mathrm{Bu}$ ifade probleme uygulanmış, bulunan düzgün olmayan (non-uniform) alan ifadesi Detour parametresi kullanılarak, Fresnel fonksiyonunun asimptotik ilişkilendirmesi yardımıyla düzgün (uniform) hale getirilmiştir. Bu problemi, benzer şekilde kırınan alanlar için inceleyen Umul Y.Z.'nin, SKD'nin Uniform Teorisi ile sonuçlar grafiksel olarak karşılaştırılmış ve saçılan alanlar için genişletilmiştir. Sonuç olarak, saçılan düzgün (uniform) alanlar hesap edilmiş, elde edilen alan ifadeleri, farklı açıklık yarıçapları ve gözlem mesafeleri için grafikler ile değerlendirilerek yorumlanmıştır. Böylece, opak bir yüzey üzerindeki dairesel açıklıktan saçılan düzgün (uniform) alanlar SKD Teorisi yaklaşımı ile ilk kez hesaplanmıştır.

Anahtar Kelimeler: Sınır Kırınım Dalgası Teorisi (SKDT), Kırınan Alan, Saçılan Düzgün (Uniform) Alan, Detour Parametresi, Fresnel Fonksiyonu, Opak Yüzey

\section{Calculation of Scattered Fields from the Circular Aperture on an Opaque Surface}

\begin{abstract}
In this study, using the Boundary Diffraction Wave Theory approach, the calculation of scattered fields from the circular aperture on an opaque surface was investigated. Initially, the symbolic expression of the vector potential introduced by Miyamoto and Wolf was used in the BDW Theory integral. This expression was applied to the problem and the non-uniform field expression found was made uniform with the help of the asymptotic association of the Fresnel function, using the Detour parameter. With the Uniform Theory of BDW Umul Y.Z.'s which examines this problem for similarly diffracted fields, the results are compared graphically and expanded for scattered fields. As a result, the uniform scattered fields are calculated and the expressions of the field obtained were interpreted by evaluating them with the graphs obtained numerically for different aperture radii and observation distances. Thus, the expressions of uniform scattered field from the circular aperture on an opaque surface was calculated for the first time with the BDW Theory approach.
\end{abstract}

Keywords: Theory of Boundary Diffraction Wave (TBDW), Diffracted Field, Uniform Scattered Field, Detour Parameter, Fresnel Function, Opaque Surface

\footnotetext{
* Bursa Uludağ Üniversitesi, Mühendislik Fakültesi Elektrik-Elektronik Mühendisliği Bölümü, 16059 Görükle Nilüfer, BURSA

İletişim Yazarı: Mustafa ALTINEL (altinelmust@gmail.com)
} 


\section{GİRIŞ}

Sınır Kırınım Dalgası Teorisi (SKDT) uygulanma kolaylığı nedeniyle düzgün yüzeylerin kenarından kırınan alanların hesabında sıklıkla kullanılan bir yaklaşımdır. İlk olarak Young'ın kırınımın doğası ile ilgili fikirlerini geliştirmek için ele alınan Sınır Kırınım Dalgası Teorisi, birkaç bilim insanının bağımsız çabaları ile geliştirilmiştir. Young'a göre, bir kenar süreksizliği ile saçılan dalga iki alt alandan oluşmaktadır. Bunlar, süreksizliğe müdahale etmeden ilerleyen geometrik optik dalga ve kenarda oluşan kenar kırınım alanı veya SKD dir (Young, 1802). Young'ın bu düşünceleri sözel olarak ifade edildiğinden ve önemli matematiksel bulgulardan yoksun bırakıldığından dolayı ilk başlarda çok önemsenmemiştir. Yaklaşık yüzyıl kadar sonra Young'ın önerisini tekrar gündeme getiren ise Maggi ve Rubinowicz'in bağımsız olarak yaptıkları çalışmalar olmuştur (Maggi, 1888; Rubinowicz, 1917). Birbirlerinden bağımsız olarak yaptıkları bu çalışmalarda, Huygen-Kirchhoff'un yüzey integralinin doğrudan SKD'yi temsil eden bir çizgi integraline indirgenebileceğini ve kenardan kırınan alanları belirten çizgisel bir integrale dönüştürülebileceğini göstermişlerdir. Bu çalışmalar ise iki önemli gelişmeyi ortaya çıkartmıştır; yüzey integrallerinin çizgi integraline indirgenmesi ve kırınım fenomeninin doğmas1... Miyamoto ve Wolf, Maggi ve Rubinowicz tarafindan ortaya konan bu çalışmalarda, özellikle çeşitli gelen alanlar için elde edilen potansiyel fonksiyonunu genişletmiş ve SKD'nin genelleştirilmiş potansiyel fonksiyonunu elde etmişlerdir. (Miyamoto ve Wolf, 1962).

Sınır Kırınım Dalgası Teorisi açıklık sistemlerden kırınan alanların hesaplanmasında yaygın olarak kullanılmaktadır (Lit, 1972; Ganci, 1997; Ganci, 2008). Sınır Kırınım Dalgası Teorisinin çözümleri gölge bölgesinin kırınıma uğramış alanlarından elde edilmiştir. Çünkü teoride sadece açıklık yüzeyi göz önüne alınmıştır. $\mathrm{Bu}$ yüzden, bu yöntemle sadece iletilen alanlar hesaplanabilirken, yansıyan alanlar hesaplanamaz. Teori sadece opak bir yüzey üzerine kurulu olduğundan dolay1 elde edilen sonuçlar, mükemmel iletken yüzeyler ve empedans yüzeylerinden kırınan alanlar için tatmin edici sonuçlar vermez.

SKD Teorisinin avantajı, yüzey integralini çizgisel integrale dönüştürüyor olmasındadır. Kompleks geometriye sahip problemlerde, yüzey integrallerinin hesaplanması uzun işlem zamanlarına gerek duymaktadır. Ancak kırınım yüzeyi, geometrik optik dalgalara katkı sağlar ve bu dalgalar da geometrik optiklerin klasik yöntemi dikkate alınarak kolayca hesaplanabilmektedirler. Böylece, yüzey integralinin çizgisel integrale dönüştürülmüş olması, köşe kırınım dalgalarının kolayca hesaplanabilmesini ve yapılan çözümün hem daha basit hem de daha kısa sürede gerçekleşmesini sağlamaktadır.

$\mathrm{Bu}$ çalışmanın amac1, Miyamoto ve Wolf (1962) tarafından ortaya konulan vektör potansiyelinin sembolik ifadesini, SKD Teorisi integralinde kullanarak bulunan düzgün olmayan (non-uniform) alan ifadesini Detour parametresi ve Fresnel fonksiyonunun asimptotik ilişkilendirmesi yardımıyla düzgün (uniform) hale getirip, opak bir yüzey üzerindeki dairesel açıklıktan saçılan düzgün (uniform) alanların hesaplanmasıdır. Bu problemi, benzer şekilde kırınan alanlar için inceleyen SKD'nin Uniform Teorisi Umul (2009) ile sonuçlar grafiksel olarak karşılaştırılıp saçılan alanlar için genişletilmiştir. Sonuç olarak, saçılan düzgün (uniform) alanlar hesap edilip elde edilen alan ifadeleri, farklı açıklık yarıçapları ve gözlem mesafeleri için grafikler ile değerlendirilerek yorumlanmıştır. Böylece, opak bir yüzey üzerindeki dairesel açıklıktan saçılan düzgün (uniform) alanlar SKD Teorisi yaklaşımı ile ilk kez hesaplanmıştır.

Zaman faktörü çalışmanın tamamında $e^{j w t}$ olarak göz önüne alınacaktır.

\section{SINIR KIRINIM DALGASI TEORISI}

Helmholtz-Kirchoff integrali kırınım alanlarının hesabında sıklıkla kullanılır. Kapalı bir $S$ yüzeyi tarafından sınırlanmış bir $v$ hacmi içerisindeki herhangi bir $P$ noktasındaki alan dağılımı, 


$$
U(P)=\iint_{S} \vec{V}(Q, P) \cdot \vec{n} d S
$$

eşitlik (1) ile gösterildiği şekilde Helmholtz-Kirchhoff integrali ile verilebilir. Burada $\vec{n}$, kapalı yüzeyin içe doğru normal birim vektörü, $Q$ ise $S$ yüzeyi üzerindeki değişken bir noktadır. $U(P)$ ise manyetik veya elektriksel bir alan ifadesidir. Bu integral denklem homojen Helmholtz denkleminin bir çözümü olup, Stokes teoremi kullanılarak iki parçaya ayrılabilir.

$$
U(P)=U_{B}(P)+U_{G O}(P)
$$

Yukarıda verilen (2) eşitliği, SKD teorisi yaklaşımının temel eşitliğidir. Bu eşitlikte görülen ilk terim, $A$ açıklık yüzeyinin $\Gamma$ sınırından kırınan alanı temsil eder (Şekil 1) ve aşağıda gösterilen integral eşitliği (3) ile verilebilir.

$$
U_{B}(P)=\int_{\Gamma} \vec{W}(Q, P) \cdot \vec{l} d l
$$
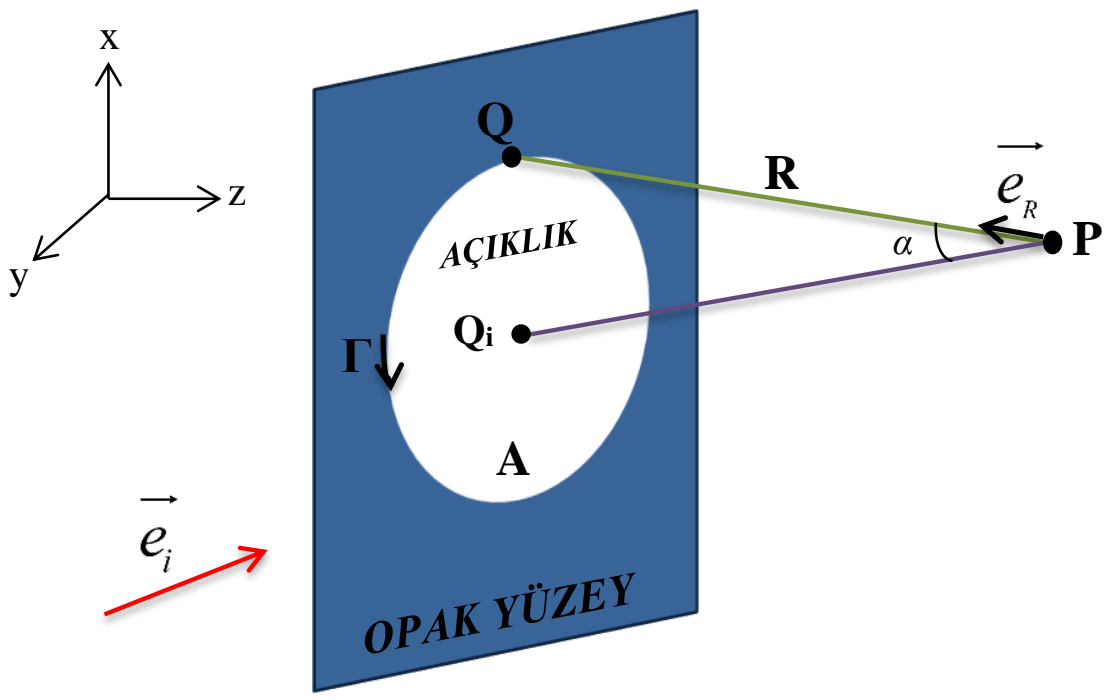

Şekil 1:

Sinır Kırınım Dalgasının Geometrisi

(3) no.lu eşitlikte görülen $\vec{l}$, açıklık yüzeyinin $\Gamma$ sınırına ait uzunluk elemanının birim vektörü olmak üzere ve $\vec{V}(Q, P)$, bir vektör potansiyelin kıvrımı olarak $\vec{W}(Q, P)$ şeklinde ifade edilebilir. Aynı eşitlikte görülen vektör potansiyeli ise sembolik olarak;

$$
\vec{W}(Q, P)=\frac{1}{4 \pi} \frac{e^{-j k R}}{R}\left[\vec{e}_{R} \times \frac{\nabla_{Q}}{\left(-j k+\vec{e}_{R} \cdot \nabla_{Q}\right)} U(Q)\right]
$$

yukarıda (4) eşitliğinde verildiği şeklinde ifade edilebilir (Miyamoto ve Wolf, 1962). Burada $\vec{e}_{R} ; \vec{R}$ vektörünün birim vektörü olup, $R$ gözlem noktası $P$ ile $Q$ noktası arasındaki mesafeyi gösterir (Şekil 1). $k$ ise, boş uzayın dalga sayısıdır ve $k=2 \pi / \lambda$ ile verilebilir. (2) eşitliğinde görülen ikinci terim ise vektör potansiyelinin tekillikleri olup Geometrik Optik alanlarının 
katkısını temsil etmektedir. Tüm bu tekil ve ayrık noktaların yarıçapı $\sigma_{i}$ ve çevresi $\Gamma_{i}$ sınır çizgisi ile çevrelendiği düşünülürse bu terim temsili olarak;

$$
U_{G O}(P)=\sum_{i} \lim _{\sigma_{i} \rightarrow 0} \int_{\Gamma_{i}} \vec{W}\left(Q_{i}, P\right) \cdot l d l
$$

şeklinde verilebilir (Miyamoto ve Wolf, 1962; Yalçın, 2010).

\section{DAİRESEL AÇIKLIKTAN KIRINAN ALANLARIN HESABI}

Opak bir yüzey üzerindeki dairesel açıklıktan kırınım, geometrisi Şekil 2'de görüldüğü gibi Sınır Kırınım Dalgası Teorisi yöntemi ile uniform olarak hesaplanmıştır. Opak yüzeylerde yansıma olmadığından dolayı kırınan alan ifadeleri hesaplanırken ifadelerin içerisinde sadece gelen alanın katkısı bulunur. Gözlem noktası $P$ için gelen homojen düzlemsel dalga (6) no.lu eşitlikte verilmiştir.

$$
U_{i}(P)=u_{i} e^{-j \overrightarrow{k_{i} \cdot \vec{r}}}
$$

Burada $\vec{r} ; P$ noktasının pozisyon vektörü olup, $\vec{k}_{i}$ ise z birim vektörü yönündedir.

$$
\begin{gathered}
\vec{r}=x \vec{e}_{x}+y \vec{e}_{y}+z \vec{e}_{z} \\
\overrightarrow{e_{i}}=\overrightarrow{e_{z}}=-\cos \varphi \overrightarrow{e_{x}}-\sin \varphi \overrightarrow{e_{y}} \\
\vec{k}_{i}=k \overrightarrow{e_{i}}=k \overrightarrow{e_{z}}
\end{gathered}
$$

Buradan da gelen homojen düzlemsel dalga;

$$
U_{i}(P)=u_{i} e^{-j k r \cos \theta}
$$

eşitlik (10) ile ifade edilebilir. $R_{e}$ ifadesi ise $P$ gözlem noktasıyla açıklık sınırı $\Gamma$ arasındaki mesafeyi verir (Şekil 2).

$$
R_{e}=\|\vec{R}\|=\left[\left(x-x^{\prime}\right)^{2}+\left(y-y^{\prime}\right)^{2}+\left(z-z^{\prime}\right)^{2}\right]^{1 / 2}
$$

Eşitlik (11)'de $R_{e}$ 'nin formülasyonu için verilen x, y ve z değerleri,

$$
\left.\begin{array}{l}
x=r \cos \phi \sin \theta \\
y=r \sin \phi \sin \theta \\
z=r \cos \theta
\end{array}\right\} \begin{aligned}
& x^{\prime}=a \cos \phi^{\prime} \\
& y^{\prime}=a \sin \phi^{\prime} \\
& z^{\prime}=0
\end{aligned}
$$

eşitlik (12) de gösterildiği gibi olduğundan, 


$$
\begin{gathered}
\left(x-x^{\prime}\right)^{2}=\left[(r \cos \phi \sin \theta)-\left(a \cos \phi^{\prime}\right)\right]^{2}=r^{2} \cos ^{2} \phi \sin ^{2} \theta-2 r a \cos \phi^{\prime} \cos \phi \sin \theta+a^{2} \cos ^{2} \phi^{\prime} \\
\left(y-y^{\prime}\right)^{2}=\left[(r \sin \phi \sin \theta)-\left(a \sin \phi^{\prime}\right)\right]^{2}=r^{2} \sin ^{2} \phi \sin ^{2} \theta-2 r a \sin \phi \sin \phi^{\prime} \sin \theta+a^{2} \sin ^{2} \phi^{\prime} \\
\left(z-z^{\prime}\right)^{2}=[(r \cos \theta)-0]^{2}=r^{2} \cos ^{2} \theta
\end{gathered}
$$

(13), (14) ve (15) eşitlikleri (11) ifadesinde yerine konularak;

$$
R_{e}=\left[r^{2}+a^{2}-2 r a \sin \theta \cos \left(\phi-\phi^{\prime}\right)\right]^{1 / 2} \rightarrow R_{e}=\sqrt{r^{2}+a^{2}-2 r a \sin \theta}
$$

$R_{e}$ 'nin bulunabilmesi için (16) eşitliği elde edilir.

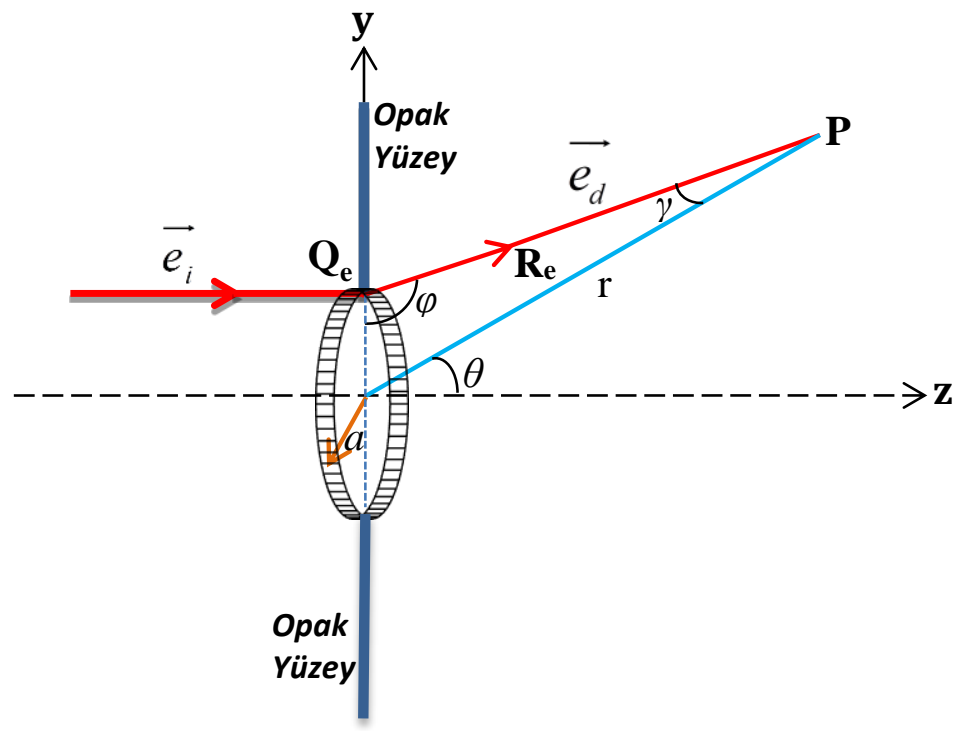

Şekil 2:

Gelen Alanın Opak Yüzey Üzerindeki Dairesel Bir Açıklıktan Kırınım Geometrisi

$U(Q)$ 'nun gradyentini ise (yansıma olmayacağından),

$$
\nabla_{Q} U(Q)=-j k u_{i} \vec{e}_{i}
$$

(17) eşitliği ile ifade edebiliriz. (10) ve (17) ifadelerini, vektör potansiyelinin sembolik ifadesi olan (4) no.lu eşitlikte kullanarak, opak bir yüzey için düzlemin vektör potansiyelini eşitlik (18),

$$
W(Q, P)=u_{i} \frac{1}{4 \pi} \frac{e^{-j k R}}{R}\left(\frac{\vec{e}_{R} \times \vec{e}_{i}}{1+\vec{e}_{R} \cdot \vec{e}_{i}}\right)
$$


şeklinde yazabiliriz. Burada $\vec{e}_{i}$ gelen alanın birim vektörüdür ve $\vec{e}_{z}$ birim vektörüne eşittir. Şekil 1 ve Şekil 2 göz önüne alınarak ilgili vektörleri $\left(\vec{e}_{R}, \vec{e}_{\rho}^{\prime}\right.$ ve $\left.\vec{e}_{r}\right)$ aşağıda (19), (20) ve (21) no.lu eşitliklerde verilen şekilde yazabiliriz.

$$
\begin{gathered}
\vec{e}_{R}=\frac{a \vec{e}_{\rho}^{\prime}-r \vec{e}_{r}}{R} \\
\vec{e}_{\rho}^{\prime}=\cos \phi^{\prime} \vec{e}_{x}+\sin \phi^{\prime} \vec{e}_{y} \\
\vec{e}_{r}=\sin \theta \cos \phi \vec{e}_{x}+\sin \theta \sin \phi \vec{e}_{y}+\cos \theta \vec{e}_{z}
\end{gathered}
$$

(19), (20) ve (21) no.lu eşitliklerde verilen bu değerler (18) no.lu ifadenin parantez içindeki kısım için yerine konulduğunda, (22) no.lu eşitlik elde edilir.

$$
\frac{\vec{e}_{R} \times \vec{e}_{i}}{1+\vec{e}_{R} \cdot \vec{e}_{i}}=\frac{\vec{e}_{x}\left(-r \sin \theta \sin \phi+a \sin \phi^{\prime}\right)+\vec{e}_{y}\left(r \sin \theta \cos \phi-a \cos \phi^{\prime}\right)}{R-r \cos \theta}
$$

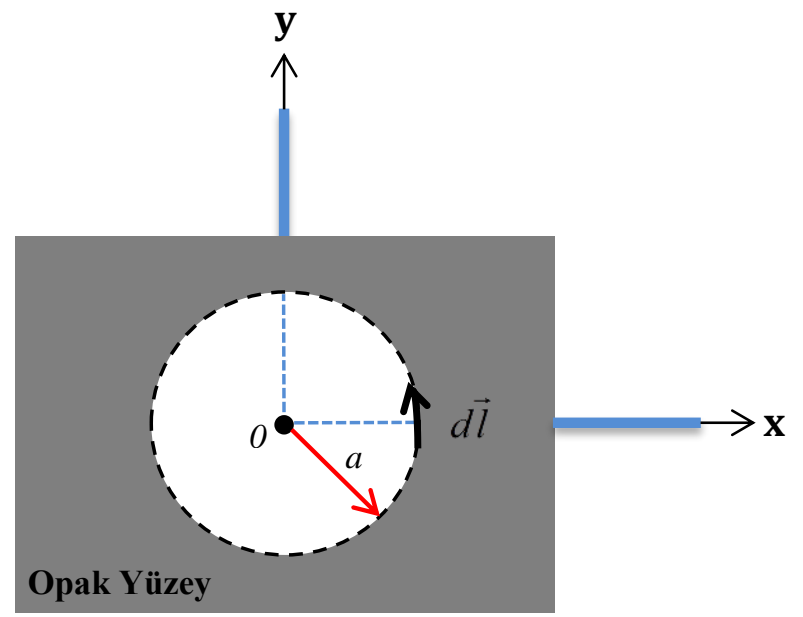

Şekil 3:

Üzerinde Dairesel Bir Açıklık Bulunan Opak Yüzeyin $(x, y)$ Düzlemindeki Görüntüsü

Yukarıda verilen Şekil 3 ve daha önce verilen Şekil 1'de de görüldüğü üzere $\vec{l} ; \Gamma_{i}$ 'nin tanjantı boyunca olan birim vektördür.

$$
d \vec{l}=a \sin \theta d \phi^{\prime} \vec{e}_{\phi}
$$

$d l$ de $\Gamma_{i}$ ' nin elemanı olup, eşitlik (23) ile gösterilebilir. Bulunan bu değerler (3) eşitliğinde yerine konulursa;

$U_{B}(P)=u_{i} \frac{a \sin \theta}{4 \pi} \int_{\phi^{\prime}=0}^{2 \pi}\left[\frac{\left(-r \sin \theta \sin \phi+a \sin \phi^{\prime}\right)\left(-\sin \phi^{\prime}\right)+\left(r \sin \theta \cos \phi-a \cos \phi^{\prime}\right) \cos \phi^{\prime}}{R-r \cos \theta}\right] \frac{e^{-j k r}}{R} d \phi^{\prime}(24)$ 
$U_{B}(P)$; açıklık yüzey sınırından $(\Gamma)$ kırınan sınır kırınım dalgası ifadesi, yukarıdaki şekilde (24) elde edilir. Buradan da gerekli sadeleştirmeler yapılarak;

$$
U_{B}(P)=u_{i} \frac{1}{4 \pi} a \sin \theta \int_{\phi^{\prime}=0}^{2 \pi}\left[r \sin \theta \cos \left(\phi-\phi^{\prime}\right)-a\right]\left(\frac{1}{R-r \cos \theta}\right) \frac{e^{-j k r}}{R} d \phi^{\prime}
$$

yukarıdaki sonuca ulaşı1ır. Bu tip hesaplanması zor integraller için stasyoner faz yöntemi kullanılarak integral alınır. Stasyoner Faz yöntemi ile;

$$
U_{B}(P) \cong U_{i} \frac{1}{2 \sqrt{2 \pi}} \sqrt{\frac{a \sin \theta}{r}}(r \sin \theta-a)\left[\frac{1}{R_{e}-r \cos \theta}\right] \frac{e^{-j k R_{e}-j \pi / 4}}{\sqrt{k R_{e}}}
$$

bu integral alınarak (26) sonucu elde edilir.

$U_{B}(P)$; açıklık yüzeyi $\Gamma$ sınırından kırınan sınır kırınım dalgasını ifade eder. Yüzeyimiz opak olduğu ve bu sebeple yansıma olmayacağı için (26) ifadesi bizim için yeterlidir. Eğer yüzeyimiz mükemmel iletken (PEC) veya empedans yüzeyi gibi yansıma olan bir yüzey olsaydı bu eşitlik kırınan alanları hesaplamak için yeterli olmayacak, parantezin içine yansımayı da hesaba katıp Genişletilmiş Sınır Kırınım Dalgası Teorisi ile ikinci bir terim eklemek durumunda kalacaktık (Yalçın, 2009).

Sonraki adım olarak Fresnel fonksiyonuna geçiş yapılması gerekmektedir. Burada Fresnel fonksiyonumuz (27) no.lu eşitlikte verilmiştir.

$$
\hat{F}\left(\xi_{i}\right)=\frac{e^{-j\left(\xi_{i}^{2}+\pi / 4\right)}}{2 \sqrt{\pi} \xi_{i}}
$$

Burada $\xi_{i}$, Fresnel fonksiyonunun bir argümanıdır ve detour parametresini temsil eder (Lee, 1977). Detour parametresi gelen alan ile kırınan alan arasındaki faz farkı ile elde edilir. Bu ifade gösterim olarak eşitlik (28) de verilmiştir.

$$
\xi_{i}=-\sqrt{\psi_{i}-\psi_{d}}=-\sqrt{k\left(R_{e}-r \cos \theta\right)}
$$

Burada $\psi_{i}$ gelen alanın faz fonksiyonunu gösterirken $\psi_{d}$ ise kırınan alanın faz fonksiyonudur. $\mathrm{Bu}$ durumda gelen dalga için detour parametresini bulmak istersek $\psi_{i}$ yerine $U_{B i}(P)$ 'nin fazı ve $\psi_{d}$ yerine kırınan alanın fazı yazıldığında (29) ifadesi elde edilir.

$$
\xi_{i}^{2}=k R_{e}-k r \cos \theta=k R_{e}-k z
$$

Gelen alan için detour parametresinin karesi (29) ifadesindeki gibi bulunur. Gelen alan için eşitlik (26) deki ifade ile birlikte yazılırsa (30) elde edilir; 


$$
U_{B_{i}}(P)=-u_{i} \frac{1}{2 \sqrt{2 \pi}} \sqrt{\frac{a \sin \theta}{r}} \frac{(r \sin \theta-a)}{-\sqrt{k\left(R_{e}-r \cos \theta\right)}} \frac{e^{-j k R_{e}-j \pi / 4+j k z-j k z}}{\sqrt{R_{e}} \sqrt{R_{e}-r \cos \theta}}
$$

Bu ifadede Fresnel fonksiyonu yerine konularak, eşitlik (31) elde edilir.

$$
U_{B_{i}}(P)=-u_{i} \frac{1}{\sqrt{2}} \sqrt{\frac{a \sin \theta}{r}} \frac{(r \sin \theta-a) e^{-j k r \cos \theta}}{\sqrt{R_{e}\left(R_{e}-r \cos \theta\right)}} \hat{F}\left(\xi_{i}\right)
$$

Detour parametresinin de bulunmasıyla kırınan alana ait birinci uniform ifade Fresnel fonksiyonunun asimptotik ilişkilendirmesi kullanılarak bulunabilir. Örneğin burada $\hat{F}\left(\xi_{i}\right)$ yerine $\hat{F}\left(\xi_{i}\right)=\hat{F}\left(\left\|\xi_{i}\right\|\right) \operatorname{Sgn}\left(\xi_{i}\right)$ yaklaşımı kullanılmıştır. Burada $\operatorname{Sgn}\left(\xi_{i}\right)$ signum fonksiyonudur. Fresnel fonksiyonunun bu şekilde ifade edilmesinin nedeni ise aldığı değerlerin sağladığı avantajla ilgilidir. Signum fonksiyonu aşağıdaki değerleri alabilir.

$$
\operatorname{Sgn}\left(\xi_{i}\right)=\left\{\begin{array}{cc}
-1, & \xi<0 \\
0, & \xi=0 \\
1, & \xi>0
\end{array}\right.
$$

Gölge sınırı ve yansıma sınırı olarak adlandırılan, gelen dalganın kırınıma ya da yansımaya uğrayacağı bir de gelen dalganın bulunduğu üç bölge söz konusudur. Birinci bölgede gelen, yansıyan ve kırınan alanla ilgili terimler mevcuttur. İkinci bölgede gelen ve kırınan alanlara ait ifadeler varken, üçüncü bölgede ise sadece kırınan alan vardır. Durumun bu şekilde gelişmesini sağlayan olay ise kesin çözüm ifadesindeki signum fonksiyonlarıdır.

$\hat{F}\left(\xi_{i}\right)$, Fresnel integrali şu şekilde de verilebilir.

$$
\hat{F}\left(\xi_{i}\right)=\frac{e^{j \frac{\pi}{4}}}{\sqrt{\pi}} \int_{\xi_{i}}^{\infty} e^{-j t^{2}} d t
$$

Burada $\xi_{i}$ için bulunan değer yazılıp , $\xi_{i}$ ve $\infty$ aralığı boyunca integral alındığında Fresnel fonksiyonu için önceden bulunmuş olan değer yani gelen alan ifadesi elde edilmiş olur.

$$
U_{B_{i}}(P)=-u_{i} \frac{1}{\sqrt{2}} \sqrt{\frac{a \sin \theta}{r}} \frac{(r \sin \theta-a) e^{-j k r \cos \theta}}{\sqrt{R_{e}\left(R_{e}-r \cos \theta\right)}} \hat{F}\left(\left\|\xi_{i}\right\|\right) \operatorname{Sgn}\left(\xi_{i}\right)
$$

Kırınan alan; gelen ve yansıyan alanlardan oluşan katkının toplamı şeklinde gösterilir. Fakat yüzeyimiz opak olduğu ve yansıma olmadığı için kırınan alanımız sadece gelen alanın katkısına eşittir;

$$
U_{B}(P)=U_{B_{i}}(P)
$$

ve bu da (36) de verilen eşitlikle gösterilebilir. 


$$
U_{B}(P)=-u_{i} \sqrt{\frac{a \sin \theta}{2 r R_{e}}}(r \sin \theta-a)\left[\frac{e^{-j k r \cos \theta}}{\sqrt{R_{e}-r \cos \theta}} F\left(\left\|\xi_{i}\right\|\right) \operatorname{Sgn}\left(\xi_{i}\right)\right]
$$

Yukarıda verilen (36) ifadesi düzenlenirse; kırınan alan ifadesi,

$$
U_{B}(P)=-u_{i} \sqrt{\frac{a \sin \theta}{2 r R_{e}}}(r \sin \theta-a)\left[\frac{e^{-j k z}}{\sqrt{R_{e}-z}} F\left(\left\|\xi_{i}\right\|\right) \operatorname{Sgn}\left(\xi_{i}\right)\right]
$$

biçiminde elde edilir. Birim basamak fonksiyonu ise eşitlik (38) şeklindedir.

$$
u(\xi)= \begin{cases}1, & \xi>0 \\ \infty, & \xi=0 \\ 0, & \xi<0\end{cases}
$$

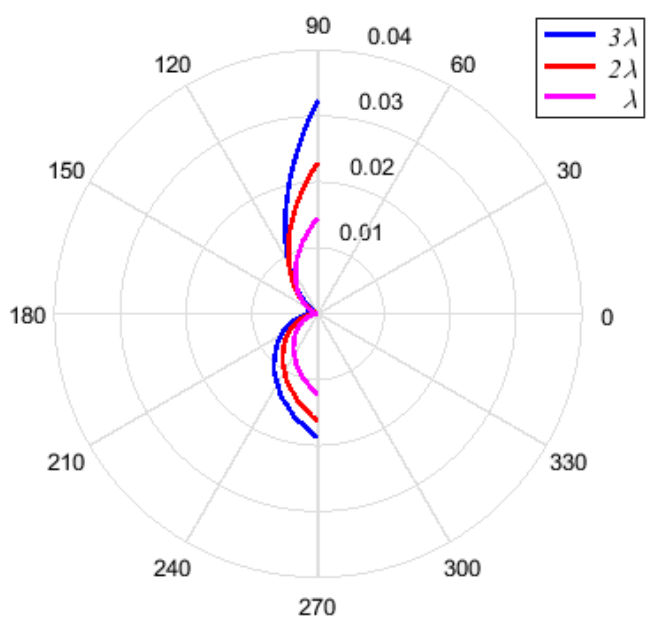

Sekil 4:

Kaynak Bölgesindeki a'ya bă̆lı Kirinan Alanlar

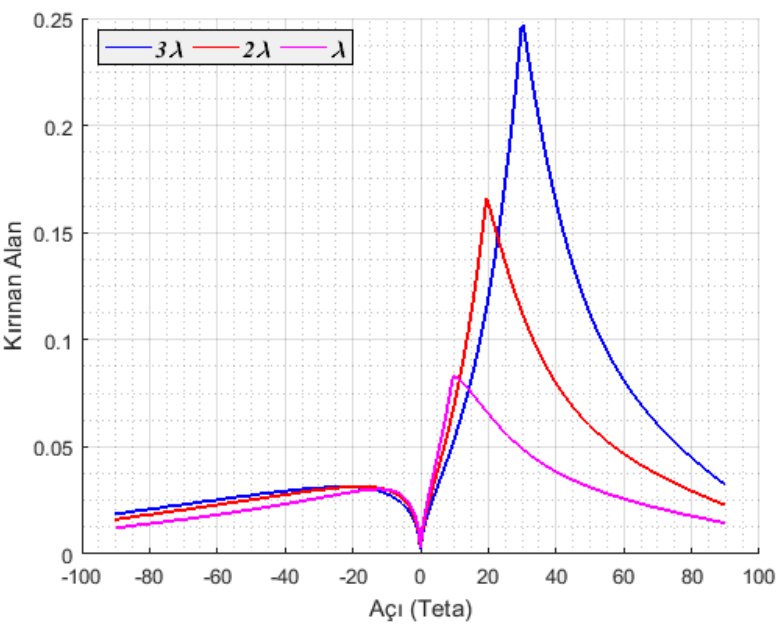

Şekil 5:

Gözlem Bölgesindeki a’ya bă̆ll Kirinan Alanlar

Yukarıdaki 4 ve 5 no.lu şekillerde $u_{\mathrm{i}}$ birim genlik seçilmiş, $r=6 \lambda$ için $a$ açıklık yarıçapının farklı varyasyonları ile $\lambda$ değerleri $(3 \lambda, 2 \lambda, \lambda)$ alınmış ve SKD teorisi yöntemi ile bulunan kaynak ve gözlem bölgesindeki kırınan alanlara ait veriler birbirinden bağımsız olarak gösterilmiştir. Burada $\lambda$ dalga boyunu göstermekte olup değeri ise $\lambda=0.1 \mathrm{~m}$.'dir. Şekil 5 'de kırınan alanın geçiş bölgesinde sonlu olduğu görülebilir.

Aşağıda verilen Şekil 6'da ise $u_{\mathrm{i}}$ birim genlik seçilmiş, $a$ açıklık yarıçapının, $a=2 \lambda$ değeri için $r$ mesafesi yarıçapının farklı varyasyonları $(3 \lambda, 6 \lambda, 9 \lambda)$ alınmış ve SKD teorisi yöntemi ile bulunan gözlem bölgesindeki kırınan alanlara ait veriler gösterilmiştir. Burada $\lambda$ dalga boyunu göstermekte olup değeri ise $\lambda=0.1$ m.' dir. Şekil 6 'da görüldüğü üzere, $r$ yarıçapı arttıkça kırınan alanın azaldığı, sıfıra yaklaştıkça bölge dışına çıktığı ve kırınıma uğramadan geçiş bölgesinden geçtiği görülmektedir. 


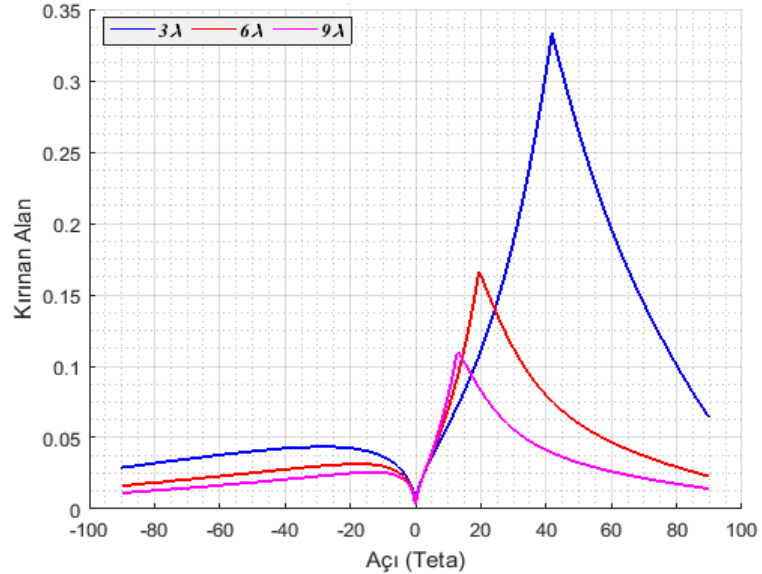

Şekil 6:

Gözlem Bölgesindeki r'ye bă̆gl Kirinan Alanlar

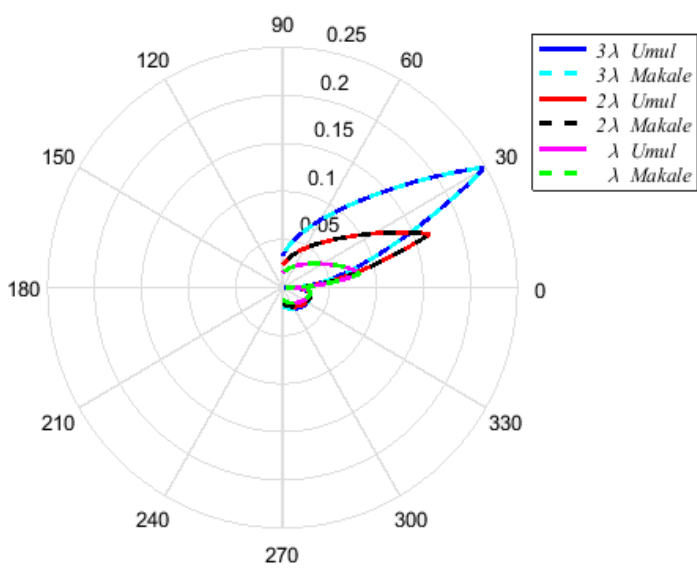

Şekil 7:

Gözlem Bölgesindeki Kırınan Alanlar için

Umul vs. Makale Karşılaştırması

Şekil 7'de ise, gözlem bölgesindeki kırınan alanlar için bulduğumuz sonuçlar, bu problemi benzer şekilde kırınan alanlar için inceleyen SKD'nin Uniform Teorisi Umul (2009) ile karşılaştııılmıştır. Şekilde, $r=6 \lambda$ ve $a$ açıklık yarıçapının farklı varyasyonları için sonuçların birebir örtüştüğü ve çizilen grafiklerin üst üste geldiği net bir şekilde görülmektedir. Açıklık yarıçap $a$ değeri azaldıkça, geçiş bölgesinin sıfıra yaklaştı̆̆ açıkça görülebilir. Bu beklenen bir sonuçtur.

\section{SAÇILAN ALANLAR VE SAYISAL SONUÇLAR}

Opak bir yüzey için, kaynak ve gözlem bölgesindeki saçılan alanlar, yansıma olmadığından birbirinden bağımsız olarak sadece gelen ve kırılan alanların toplamına eşittir. İki bölge arasındaki fark ise $\theta$ açısıdır. Aşağıda gösterilen eşitlikte; ilk terim gelen alanı, ikinci terim ise kırınan alanı göstermektedir ve eşitlik (39) ile verilebilir.

$$
U_{B_{T}}(P)=\left[\left(u_{i} e^{-j k z} u\left(-\xi_{i}\right)\right)\right]-\left(u_{i} \sqrt{\frac{a \sin \theta}{2 r R_{e}}}(r \sin \theta-a)\left[\frac{e^{-j k z}}{\sqrt{R_{e}-z}} F\left(\left\|\xi_{i}\right\|\right) \operatorname{Sgn}\left(\xi_{i}\right)\right]\right)
$$

Opak yüzeylerde yansıma olmayacağı için (daha önce bu durumu açıkladık), kaynak bölgesinde sadece gelen ve kırınan alanlar mevcuttur. Bu bölgede $\theta$ açısı değeri $\pi / 2 \leq \theta \leq 3 \pi / 2$ aralığında değişmektedir. Gözlem noktasının bulunduğu diğer bölgede ise saçılan alan ifadesinin içinde yine yansıyan alan bulunmaz ve sadece gelen ve kırınan alanlar mevcuttur. Bu bölgedeki $\theta$ açısı değeri ise $-\pi / 2 \leq \theta \leq \pi / 2$ aralığında değişmektedir. Gelen alanın her iki bölgede de bulunmasının sebebi yüzey üzerindeki açıklıktan kırınıma uğramadan geçen bölümlerinin olmasıdır. Toplam saçılan alanlar ise tüm bölgeyi kapsar ve $\theta$ değeri $0 \leq \theta \leq 2 \pi$ aralığında değişmektedir.

Aşağıda verilen grafiklerden Şekil 9, Şekil 10 ve Şekil 11'de, $u_{\mathrm{i}}$ birim genlik seçilmiş, $r=6 \lambda$ ve açıklık yarıçapı $a=2 \lambda$ alınmıştır. Şekil 8'de ise bunlardan farklı olarak $a$ açıklık yarıçapının farklı varyasyonları için $\lambda$ değerleri $(3 \lambda, 2 \lambda, \lambda)$ alınmıştır. Burada $\lambda$ dalga boyunu göstermekte olup değeri ise $\lambda=0.1 \mathrm{~m}$.'dir. SKD Teorisi yöntemi ile bulunan kaynak ve gözlem bölgeleri ile tüm bölgelerdeki kırınan, toplam ve saçılan alanlara ait veriler birbirinden bağımsız olarak gösterilmiştir. Şekil 8'den de görülebileceği üzere opak bir yüzey için kırınan alanlar kaynak bölgesinde, gözlem bölgesine oranla çok daha küçüktür. Bunun sebebi ise gelen alanın opak 
yüzeyin özelliğinden kaynaklı açıklık harici geçiş sağlayamamasıdır. Bu nedenle kaynak bölgesindeki toplam alanlar gelen alana çok yakın değerlerdeyken gözlem bölgesinde kırınan alanların, toplam alana katkısı bariz olarak görülmektedir (Sekil 9 ve 10). Fakat bu durum kaynak bölgesindeki kırınan alanların ihmal edilebileceği sonucunu vermez. Şekil 11 ise opak yüzeyin tüm bölgelerdeki $(0 \leq \theta \leq 2 \pi)$ toplam saçılımını göstermektedir. Saçılım, gözlem bölgesinde kırınıma bağlı olarak daha belirgin ve nettir.

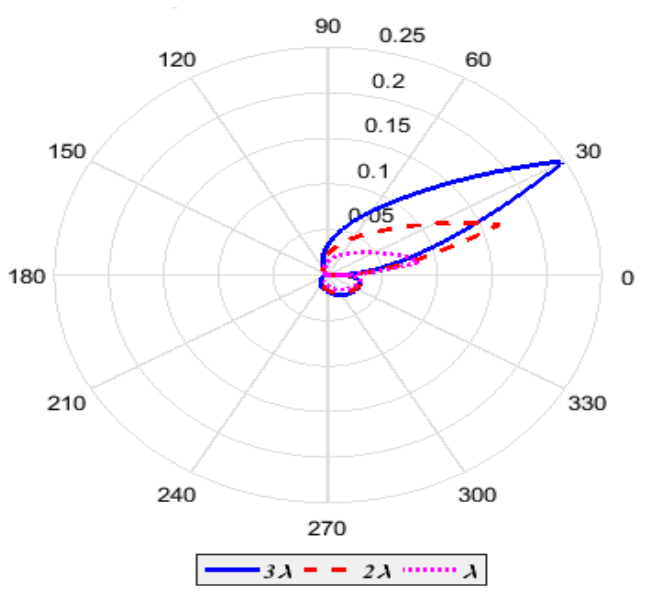

Şekil 8:

Tüm Bölgelerdeki Toplam Kırınan Alanlar

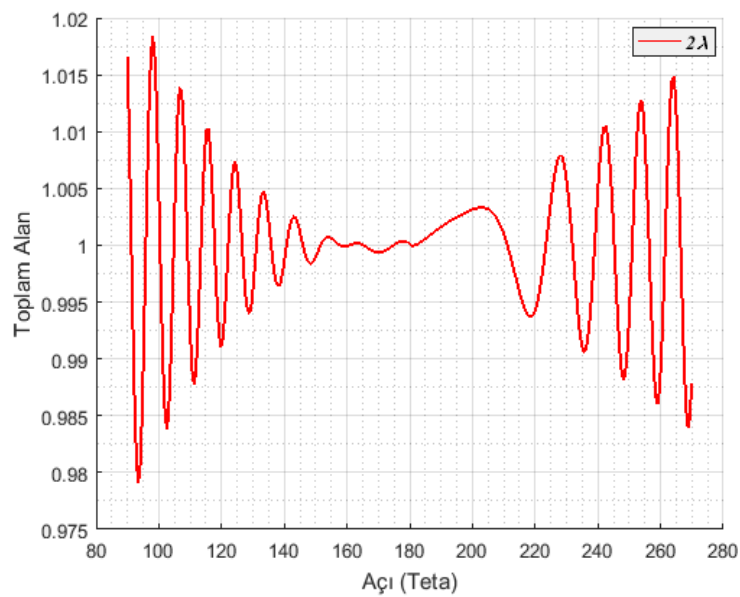

Şekil 10:

Kaynak Bölgesindeki Toplam Alanlar

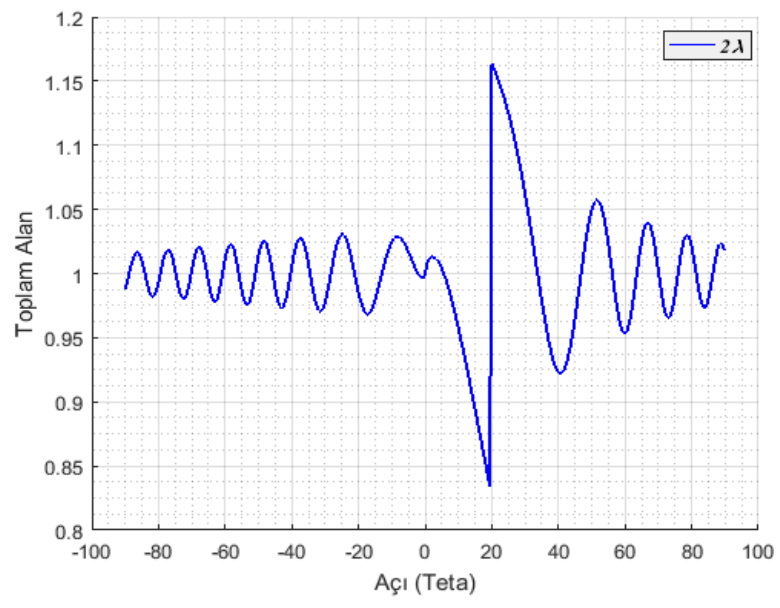

Şekil 9:

Gözlem Bölgesindeki Toplam Alanlar

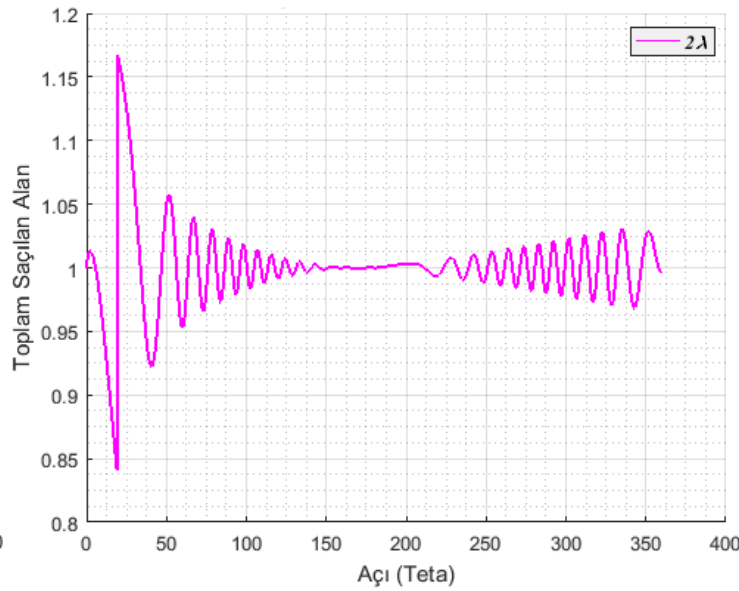

Şekil 11:

Tüm Bölgelerdeki Toplam Saçılan Alanlar

\section{SONUÇ}

Bu çalışmanın katkısı, opak bir yüzey üzerine gelen homojen düzlemsel dalganın dairesel açıklıktan saçılımının Sınır Kırınım Dalgası Teorisi (SKDT) yöntemiyle ilk kez hesaplanması ve elde edilen alan ifadelerinin, farklı açıklık yarıçapları ve gözlem mesafeleri için grafikler ile değerlendirilerek yorumlanmasıdır. İlk olarak Miyamoto ve Wolf’ün (1962) geliştirdiği vektör potansiyeli ifadesi SKD Teorisi integralinde kullanılmıştır. Bu ifade probleme uygulanmış ve 
bulunan düzgün olmayan (non-uniform) alan ifadesi Detour parametresi kullanılarak, Fresnel fonksiyonunun asimptotik ilişkilendirmesi yardımıyla düzgün (uniform) hale getirilmiştir. Elde edilen düzgün kırınan alan ifadeleri, SKD'nin Uniform Teorisi Umul (2009) ile sonuçlar grafiksel olarak karşılaştırılmış, elde edilen sonuçların birebir örtüştüğü ve çizilen grafiklerin üst üste geldiği net bir şekilde görülmüştür. Açıklık yarıçap $a$ değeri azaldıkça, geçiş bölgesinin 0'a yaklaştığı ve kırınan alanların açıklık yarıçapı $a$ 'ya ve $r$ mesafesine bağlı olarak değiştiği açıkça görülmüştür. Bu beklenen bir sonuçtur.

Sonuç olarak, opak bir yüzey üzerindeki dairesel açıklıktan saçılan alanlar, gözlem bölgesinde daha belirgin ve net görünürken, kaynak bölgesinde daha zayıftır. Fakat bu durum kaynak bölgesindeki alanların ihmal edilebileceği sonucunu doğurmaz. Bu probleme benzer şekilde çözüm getirmeyi hedefleyen Fraunhofer yöntemi ise sadece gözlem bölgesindeki alanları hesaba katıp kaynak bölgesindeki alanları ihmal eder (Hecht, 1987; Ganci, 2008).

\section{ÇIKAR ÇATIŞMASI}

Yazarlar, bilinen herhangi bir çıkar çatışması veya herhangi bir kurum/kuruluş ya da kişi ile ortak çıkar bulunmadığını onaylamaktadırlar.

\section{YAZAR KATKISI}

Mustafa ALTINEL çalışmanın kavramsal ve tasarım süreçlerinin belirlenmesi, makale taslağının oluşturulması, veri toplama ve verilerin analizi, bulguların değerlendirilmesi ve sonuçların yorumlanması aşamalarında katkı sağlamıştır. Uğur YALÇIN çalı̧̧manın kavramsal ve tasarım süreçlerinin belirlenmesi ile yönetiminde, fiziksel içeriğin incelenmesi ve fikirsel içeriğin eleştirel incelenmesi ile uygun yöntemlerle çalışmanın analizi ve sonuçların yorumlanması aşamalarında katkı sağlamıştır. Çalışmanın son onay ve tam sorumluluğunu tüm yazarlar üstlenmektedir.

\section{KAYNAKLAR}

1. Altıngöz, C. and Yalçın, U. (2013) Calculation of the diffracted waves from the edge of an opaque cut cylinder by the boundary diffraction wave theory, Journal of the Faculty of Engineering and Architecture of Gazi University, 28(1), 85-90.

2. Baker, B. and Copson, E. (1949) The Mathematical Theory of Huygens' Principle, Oxford at the Clarendon 444res. ISBN:9780828403290

3. Ganci, S. (1995) A general scalar solution for the half-plane problem, Journal of Modern Optics, 42(8), 1707-1711. doi:10.1080/09500349514551491

4. Ganci, S. (1996) Half-plane diffraction in a case of oblique incidence, Journal of Modern Optics, 43(12), 2543-2551. doi:10.1080/09500349608230680

5. Ganci, S. (1997) Boundary diffraction wave theory for rectilinear apertures, European Journal of Physic, 18, 229-236. doi:10.1088/0143-0807/18/3/018

6. Ganci, S. (2008) Diffracted wavefield by an arbitrary aperture from Maggi - Rubinowicz transformation: Fraunhofer approximation, Optics, 119(1), 41-45. doi:10.1016/j.ijleo.2006.06.007

7. Hecht, E. (1987) Definition of Fraunhofer diffraction and explanation of forms with reference to an opaque shield aperture, Journal of Modern Optics, 34(7), 396-397.

8. Keller, J. B. (1962) Geometrical optics theory of diffraction, Journal of the Optical Society of America, 52, 116-130. 
9. Lee, S. W. and Deschamps, G. A. (1976) A uniform asymptotic theory of electromagnetic diffraction by a curved wedge, IEEE Transactions on Antennas and Propagation, 24, 25-34. doi:10.1109/tap.1976.1141283

10. Lee, S. W. (1977) Comparison of Uniform Asymptotic Theory and Ufimtsev's Theory of Electromagnetic Edge Diffraction, IEEE Transactions on Antennas and Propagation, 25, 162-170. doi:10.1109/tap.1977.1141559

11. Lit J. W. Y. (1972) Boundary diffraction waves due to a general point source and their applications to aperture systems, Journal of Modern Optics, 19(12), 1007-1014. doi:10.1080/713818522

12. Liu P. ve Lü B. (2005) Diffraction of spherical waves at an annular aperture in the use of the boundary diffraction wave theory: A comparison of different diffraction integral approaches, Optics, 116, 449-453. doi:10.1016/j.ijleo.2005.01.037

13. Maggi, G. A. (1888) Sulla propagazione libera e perturbata delle onde luminose in un mezzo izotropo, Annali di Matematica Pura ed Applicata, 16, 21-48. doi:10.1007/BF02420290

14. Miyamoto K. and Wolf E. (1962) Generalization of the Maggi-Rubinowicz theory of the boundary diffraction wave: Part I, Journal of the Optical Society of America, 52(6), 615625. doi:10.1364/JOSA.52.000615

15. Miyamoto K. and Wolf E. (1962) Generalization of the Maggi-Rubinowicz theory of the boundary diffraction wave: Part II, Journal of the Optical Society of America, 52(6), 626636. doi:10.1364/JOSA.52.000626

16. Otis G. (1974) Application of the boundary diffraction wave theory to Gaussian beams, Journal of the Optical Society of America, 64(11),1545-1550. doi:10.1364/JOSA.64.001545

17. Rubinowicz, A. (1917) Die beugung swelle in der Kirchoffschen theorie der

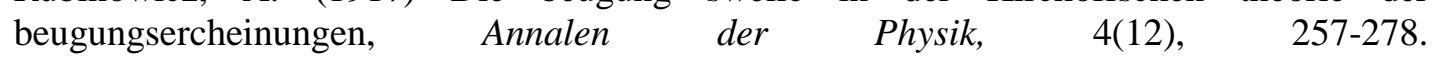
doi:10.1002/andp.19173581202

18. Tang L. and others (2005) Analysis of near-field diffraction pattern of a metallic probe tip with the boundary diffraction wave method, Chinese Physics Letters, 22(9), 2443-2446.

19. Umul, Y. Z. (2008) Uniform line integral representation of edge-diffracted fields, Journal of the Optical Society of America, 25, 133-137. doi:10.1364/JOSAA.25.000133

20. Umul, Y. Z. and Yalçın, U. (2008) Effect of impedance boundary conditions on the potential function of the boundary diffraction wave theory, Optics Communications, 281, 23-27. doi:10.1016/j.optcom.2007.09.010

21. Umul, Y. Z. (2009) Uniform theory of the boundary diffraction wave, Optics \& Laser Technology, 41, 285-288. doi:10.1016/j.optlastec.2008.06.007

22. Yalçın, U. (2009) Uniform scattered fields of the extended theory of the boundary diffraction wave for PEC surfaces, Progress in Electromagnetics Research M, 7, 29-39. doi:10.2528/PIERM09031201

23. Yalçın, U. (2010) Gauss ışınlarının saçılmasının sınır kırınım dalgası teorisi ile incelenmesi, Uludağ Üniversitesi Mühendislik-Mimarlık Fakültesi Dergisi, 15(2), 1-7.

24. Yalçın, U. (2019) Sınır kırınım dalgası teorisi ile yarım düzlemden bessel ışınlarının kırınımı, Uludăg Üniversitesi Mühendislik Fakültesi Dergisi, 24(1), 331-341. doi:10.17482/uumfd.330411

25. Young, T. (1802) On the theory of light and colours, Philosophical Transactions Royal Society, 92 , 12-48. doi:10.1098/rstl.1802.0004 
